\title{
Charge-Shifting Cationic Polymers that Promote Self- Assembly and Self-Disassembly with DNA
}

\author{
Xianghui Liu, Jennifer W. Yang, Adam D. Miller, Elizabeth A. Nack, and David M. Lynn* \\ Department of Chemical and Biological Engineering, University of Wisconsin - Madison, \\ 1415 Engineering Drive, Madison, Wisconsin 53706
}

\section{Supporting Information}

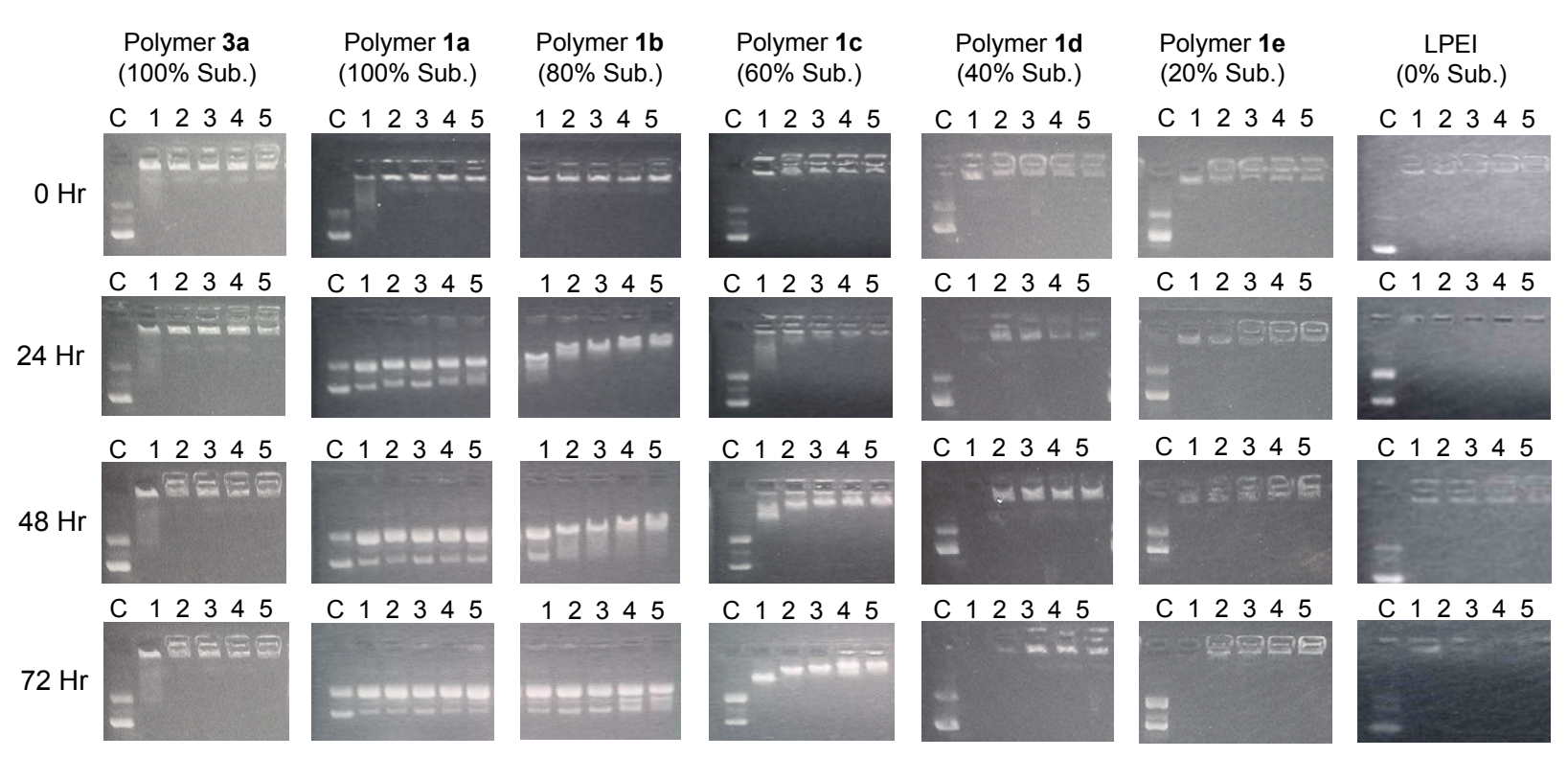

Figure S1: Extended version of Figure 3 shown in main text. Agarose gel electrophoresis experiments showing time courses for the release of DNA from DNA/polymer complexes formed using amide-functionalized polymer 3a, ester-functionalized polymers 1a-e, and LPEI controls at $0 \mathrm{hr}, 24 \mathrm{hr}, 48 \mathrm{hr}$, and $72 \mathrm{hr}$. The leftmost lane in each gel (labeled ' $\mathrm{C}$ ') corresponds to a DNA control (no polymer added). Lanes labeled 1-5 in each gel correspond to DNA/polymer ratios (w/w) of 1:1, 1:3, 1:5, 1:7, and 1:9, respectively. Note: the DNA control in lane ' $\mathrm{C}$ ' shown in column 2 (for experiments using polymer 1a) serves as the internal DNA control for the data located in column 3 (for experiments using polymer 1b). These experiments were conducted in the same row of lanes but have been separated in the figure to enhance the clarity and readability of the figure. Time courses for any individual polymer should be read in columns from top to bottom. Comparisons of release profiles among different polymers at any given time point should be made in rows from left to right. 